\title{
Comparative Analysis of High Frequency Characteristics of DDR and DAR IMPATT Diodes
}

\author{
Alexander Zemliak \\ Puebla Autonomous University \\ Mexico \\ National Technical University of Ukraine "KPI" \\ Ukraine
}

\section{Introduction}

IMPATT (IMPact Avalanche ionization and Transit Time) diodes are principal active elements for use in millimetric generators. Semiconductor structures suitable for fabrication of continuos-mode IMPATT diodes have been well known for a long time (Scharfetter \& Gummel, 1969; Howes \& Morgan, 1976). They have been utilized successfully in many applications in microwave engineering. The possibilities of using the same structures for pulsed-mode microwave generators were realized too. Considering, that the increase of the output power of millimetric generators is one of the main problems of microwave electronics; it is important to optimize the diode's active layer to obtain the generator maximum power output. From the beginning (Read, 1958) the main idea to obtain the negative resistance was defined on the basis of the phase difference being produced between RF voltage and RF current due to delay in the avalanche build-up process and the transit time of charge carriers. The single drift region (SDR) and the double drift region (DDR) IMPATT diodes are very well known (Scharfetter \& Gummel, 1969; Howes \& Morgan, 1976; Fong \& Kuno, 1979; Chang, 1990) and used successfully for the microwave power generation in millimeter region. The transit time delay of both types of diodes is the essential factor of the necessary phase conditions to obtain negative resistance. The typical DDR diode structure is shown on Fig. 1(a) by curve 1 , where $N$ is the concentration of donors and acceptors, $l$ is the length of diode active layer. In this type of diodes, the electrical field is strongly distorted when the avalanche current density is sufficiently high. This large space charge density is one of the main reasons for the sharp electrical field gradient along the charge drift path. Because of this field gradient, the space charge avalanche ruins itself and consequently the optimum phase relations degrade between microwave potential and current. This factor is especially important when the IMPATT diode is fed at the maximum current density, which is exactly the case at the pulsedmode operation. The idea to use a complex doping profile semiconductor structure for microwave diode was originally proposed in the first analysis of IMPATT diode by (Read, 1958). This proposed ideal structure has never been realized till now. However, a modern semiconductor technology provides new possibilities for the fabrication of sub micron semiconductor structures with complex doping profiles. This stimulates the search for IMPATT-diode special structure's optimization.

Source: Micro Electronic and Mechanical Systems, Book edited by: Kenichi Takahata, ISBN 978-953-307-027-8, pp. 572, December 2009, INTECH, Croatia, downloaded from SCIYO.COM 


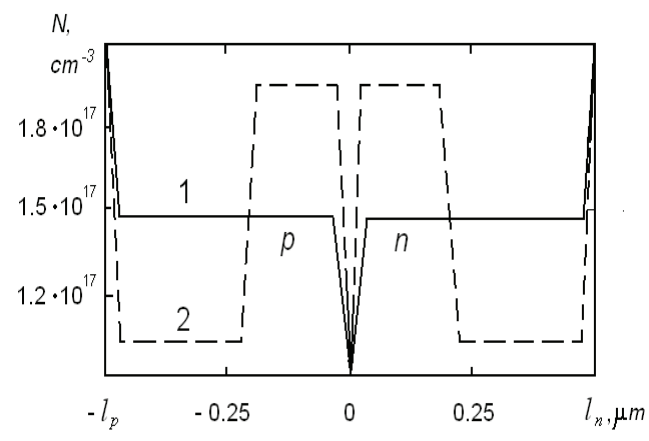

(a)

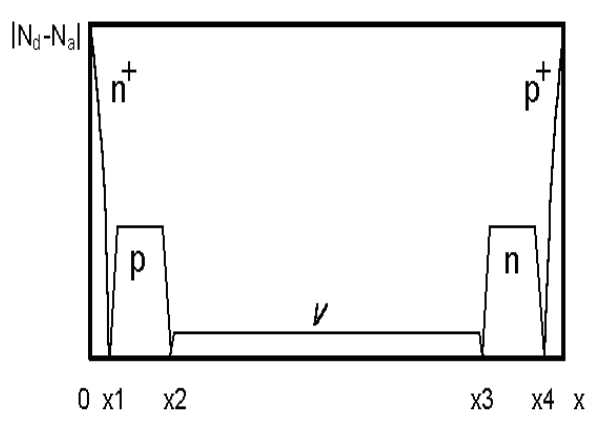

(b)

Fig. 1. (a) Doping profile for two types of DDR IMPATT diodes: 1- constant doping profile; 2- quasi-Read-type doping profile; (b) Doping profile for DAR type of IMPATT diode

The other proposed DDR type of IMPATT diode doping profile is shown on the Fig. 1(a) by the curve 2. This type of semiconductor structure can be named as quasi-Read-type structure. This type of doping profile provides a concentration of electrical field within the $p-n$ junction. This measure helps to decrease the destruction of the avalanche space charge and therefore permits to improve the phase stability between the diode current and voltage. The DDR type of IMPATT diode produces one frequency band only in practice because a very strong losses for high frequency bands. The typical small signal admittance characteristic of DDR diode is shown in Fig. 2.

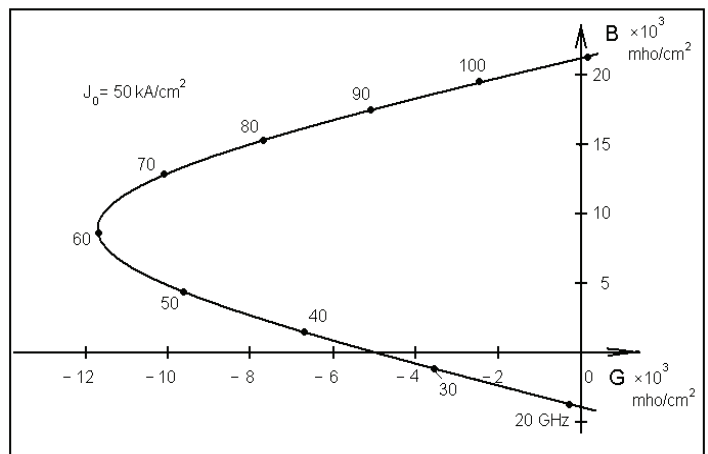

Fig. 2. Complex small signal DDR diode admittance (conductance $-G$ versus susceptance $B$ ) for different frequencies

However a diode that has two avalanche regions can produce an avalanche delay which alone can satisfy conditions necessary to generate microwave power. In this case the phase delay of the drift zone becomes subsidiary. The DAR diode can be defined for instance by means of the structure n+ponp+ in Fig. 1(b).

The DAR diode has two avalanche regions around $n+p$ and $n p+$ junctions and one common drift region. This type of diode was suggested in (Som et al., 1974). The characteristics of this diode were analyzed in DC and RF modes (Datta \& Pal, 1982; Datta et al., 1982; Pati et al., 1991; Panda et al., 1995). The authors affirm that the avalanche delay produced by each of 
the thin avalanche regions becomes nearly 
diode. We have modified the local-field electrical model (Zemliak \& De La Cruz, 2002) to calculate the functional dependence of equation coefficients from electric field, and using all these data finally we derive the IMPATT-diode dynamic characteristics.

\section{Numerical models}

Two different numerical models are described in this section. The first model is useful for the precise analysis of the internal structure of IMPATT diode and it describes all the most important phenomena into the semiconductor structure. The other model is approximate and it is useful during the process of the internal structure optimization.

\subsection{Precise numerical model}

The numerical model developed for the analysis of various generator operation modes. This model is based on the system of continuity equations for semiconductor structure: 
The boundary conditions for the system (1) can be written as follows: 
where $a_{n, p} \frac{D_{n, p}}{2 h^{2}}$ 
The charge diffusion and sharp dependence of the ionization coefficients on the electrical field determine the great module of eigenvalues of the matrix $A$. For this case, a shooting method, which reduces a boundary problem to Cauchy problem, is not suitable because coordinate basis degenerates in the solution process and therefore is not stable. The boundary problem (9) is solved on the basis of the functional matrix correlation (Bakhvalov et al., 1987): 
These data are corresponded to the nonlinear modes with an average level of the nonlinearity. For this case we determine error as the relative difference of the diode admittance value that we obtain by this harmonic method and by more precise numerical method of the section 2.1. It is clear that the harmonic number $M$ more than 12-15 is sufficient to obtain a good accuracy of the diode parameters. At the same time we have a significantly reducing of the total computer time. Computer time for one probe of diode analysis is the principal characteristic of the optimization procedure. That is the main reason why this approximate model is elaborated. For example the total computer time for the diode analysis by precise numerical model is corresponded to the number of harmonic $M=40$.

\section{Optimization procedure}

The optimization algorithm was designed as the combination of one of kind of direct method and a gradient method. This is one of the modification of well-known algorithm, which is successfully used for function with complicate structure. This method is more precisely successful for the optimization of millimetric wave devices because the objective function of that type of devices as the function of its arguments has a very complex behavior similar to a one "valley" in N-dimensional space. The objective function can be determined as the maximum electronic power, for example. The number of free variables depends on the diode structure. For the DDR diode structure optimization with constant doping profile we need to define 4 parameters: two lengths and two doping profile levels. For the DDR quasi-Read diode structure optimization we need to define 8 parameters: four lengths and four doping profile levels. We have been formed the principal vector of variables $y$ for some parameters of semiconductor structure.

The optimization algorithm consists of the next steps:

1. Given as input two different approximations of two initial points: $y^{0}$ and $y^{1}$.

2. At these points, we start by gradient method, and have performed some steps. As a result, we have two new points $Y^{0}$ and $Y^{1}$. 
The optimization process that is presented above cannot find the global minimum of the objective function, but only a local one. To obtain the confidence that we have the better solution of the optimum procedure, it is necessary to investigate $\mathrm{N}$-dimensional space with different initial points. In that case, it is possible to investigate $\mathrm{N}$-dimensional volume in more detail. During the optimization process, it is very important to localize the subspace of the $\mathrm{N}$-dimension optimization space for more detail analysis. $\mathrm{N}$-dimensional space volume of independent parameters is determined approximately on the base of model described in section 2.2 for the first stage of optimization procedure. In that case, a Fourier series approximation of principal functions is used and because of this approximate model, we have a ten times acceleration. After that, on the basis of the precise model described in section 2.1 we have analyzed the internal structure of the different types of silicon diode.

\section{DDR diode analysis}

\subsection{GHz diode}

In Fig.5 (a), (b) the characteristics of power-level and efficiency for the constant profile DDR diode and complex profile DDR diode for $94 \mathrm{GHz}$ are presented as functions of feeding current density $I_{0}$ for the optimum structures and for others that are near the optimum. Parameters of these structures are presented in Table 1 and Table 2.

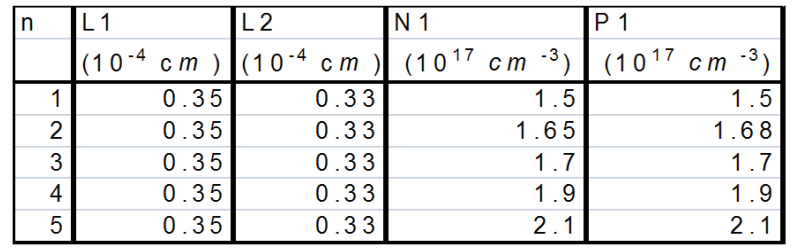

Table 1. Internal structure parameters for diode with constant doping profile for $94 \mathrm{GHz}$

\begin{tabular}{|c|c|c|c|c|c|c|c|c|}
\hline $\mathrm{n}$ & $\begin{array}{l}\mathrm{L} 1 \\
\left(10^{-4} \mathrm{~cm}\right)\end{array}$ & $\begin{array}{l}\mathrm{L} 2 \\
\left(10^{-4} \mathrm{~cm}\right.\end{array}$ & $\begin{array}{l}\text { L3 } \\
\left(10^{-4} \mathrm{~cm}\right)\end{array}$ & $\begin{array}{l}4 \\
\left(10^{-4} \mathrm{~cm}\right)\end{array}$ & $\begin{array}{l}\mathrm{N} 1 \\
\left(10^{17} \mathrm{~cm}^{-3}\right)\end{array}$ & $\begin{array}{l}\mathrm{N} 2 \\
\left(10^{17} \mathrm{~cm}^{-3}\right)\end{array}$ & $\begin{array}{l}\text { P 2 } \\
\left(10^{17} \mathrm{~cm}^{-3}\right)\end{array}$ & $\begin{array}{l}\text { P } 1 \\
\left(10^{17} \mathrm{~cm}^{-3}\right)\end{array}$ \\
\hline 1 & 0.086 & 0.283 & 0.266 & 0.084 & 1.3 & 2 & 2 & 1.3 \\
\hline 2 & 0.065 & 0.212 & 0.203 & 0.063 & 1.3 & 2 & 2 & 1.3 \\
\hline 3 & 0.072 & 0.236 & 0.222 & 0.072 & 1.3 & 2 & 2 & 1.3 \\
\hline 4 & 0.072 & 0.236 & 0.222 & 0.072 & 1.56 & 2.4 & 2.4 & 1.56 \\
\hline
\end{tabular}

Table 2. Internal structure parameters for diode with complex doping profile for $94 \mathrm{GHz}$

The parameters for optimization procedure for DDR diode with constant doping profile are defined as: $L 1$ is the length of $n$ region, $L 2$ is the length of $p$ region, N1 and P1 are the doping profile level for $n$ and $p$ regions accordingly. Structure 4 in Fig. 5(a) has the maximum power level $436 \mathrm{~kW} / \mathrm{cm}^{2}$ and the optimal current density value $I_{0}=140 \mathrm{kA} / \mathrm{cm}^{2}$. In that case, the efficiency is equal to $11.2 \%$ for the maximum power point. Structure 5 has a maximum efficiency as the function of the current $I_{0}$, but for the optimum power point this value no larger than for structures 2, 3 and 4. Besides, for this structure it is necessary to increase the current value until $153 \mathrm{kA} / \mathrm{cm}^{2}$ to obtain of the optimum power point. Semiconductor structures with a complex doping profile are analyzed to improve the power level and efficiency of pulsed-mode IMPATT diode (Fig. 5(b)). In that case eight parameters have been varied: $L 1, L 2, L 3, L 4, N 1, N 2, P 2, P 1$. $L 1$ is the length of $n$ region with low level of doping, $L 2$ 
is the length of $n$ region with high level of doping, $L 3$ is the length of $p$ region with high level of doping, L4 is the length of $p$ region with low level of doping, N1 and N2 are the low and high levels of doping for $n$ region, and $P 1$ and $P 2$ are the low and high levels of doping for $p$ region. Structure 3 is the optimal one and has an efficiency of about $15 \%$ and 446 $\mathrm{kW} / \mathrm{cm}^{2}$ power level at $123 \mathrm{kA} / \mathrm{cm}^{2}$. Others structures are near this optimum one but have a lower power level and efficiency. The extension of doping level high parts (structure 1) or increasing this level (structure 4) results to moving the power curve to the greater current density.

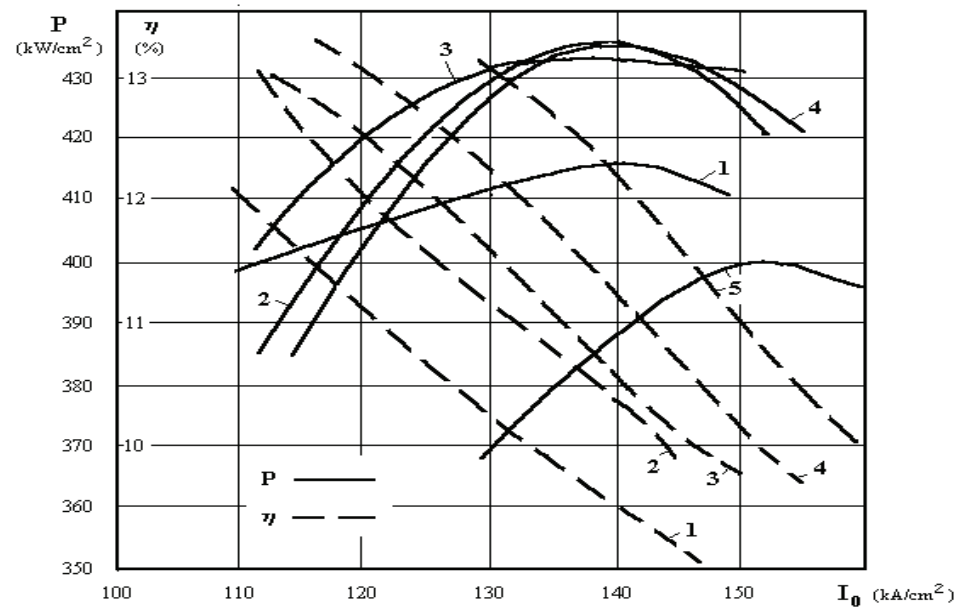

(a)

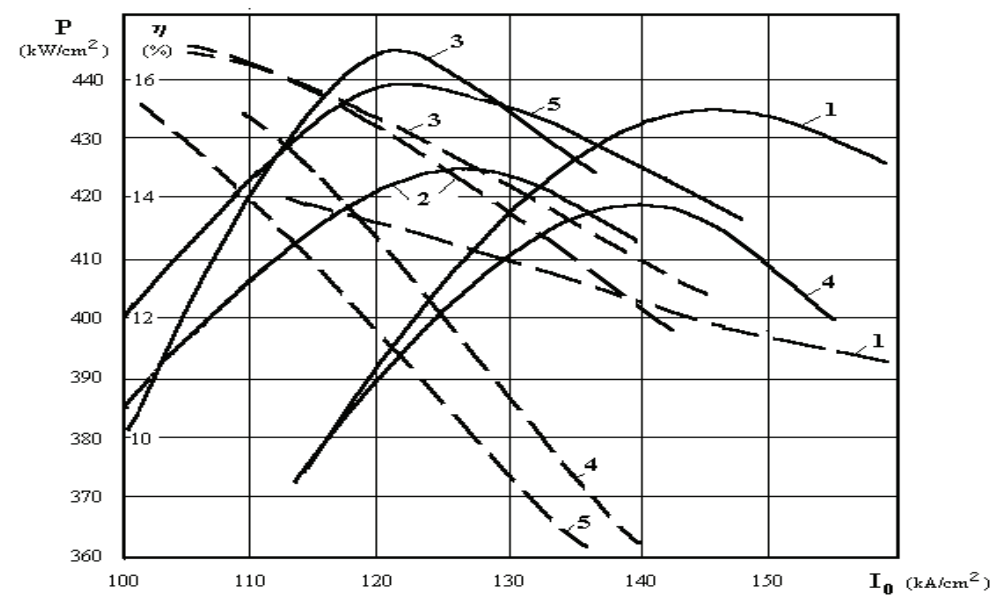

(b)

Fig. 5. Output power $\mathrm{P}$ and efficiency coefficient $\eta$ as functions of the feeding current density $I_{0}$ for optimum and near optimum structures for (a) constant and (b) complex doping profile DDR diode 
Comparison of the optimal characteristics for two different types of the structures as a constant doping profile (curve 4, Fig. 5a) and complex doping profile (curve 3, Fig. 5b) shows that the maximum output power level is almost equal for two these optimal structures $\left(436 \mathrm{~kW} / \mathrm{cm}^{2}\right.$ and $\left.446 \mathrm{~kW} / \mathrm{cm}^{2}\right)$, but efficiency coefficient has more difference $(11.2 \%$ and $14.4 \%)$. The most important fact is a significant decrease of optimal value of permanent current density for the complex doping structure. The optimal current density value for this case is equal to $140 \mathrm{kA} / \mathrm{cm}^{2}$ for the constant doping structure, but for the complex doping structure is equal to $123 \mathrm{kA} / \mathrm{cm}^{2}$. Therefore the complex doping profile structure has better energy characteristics.
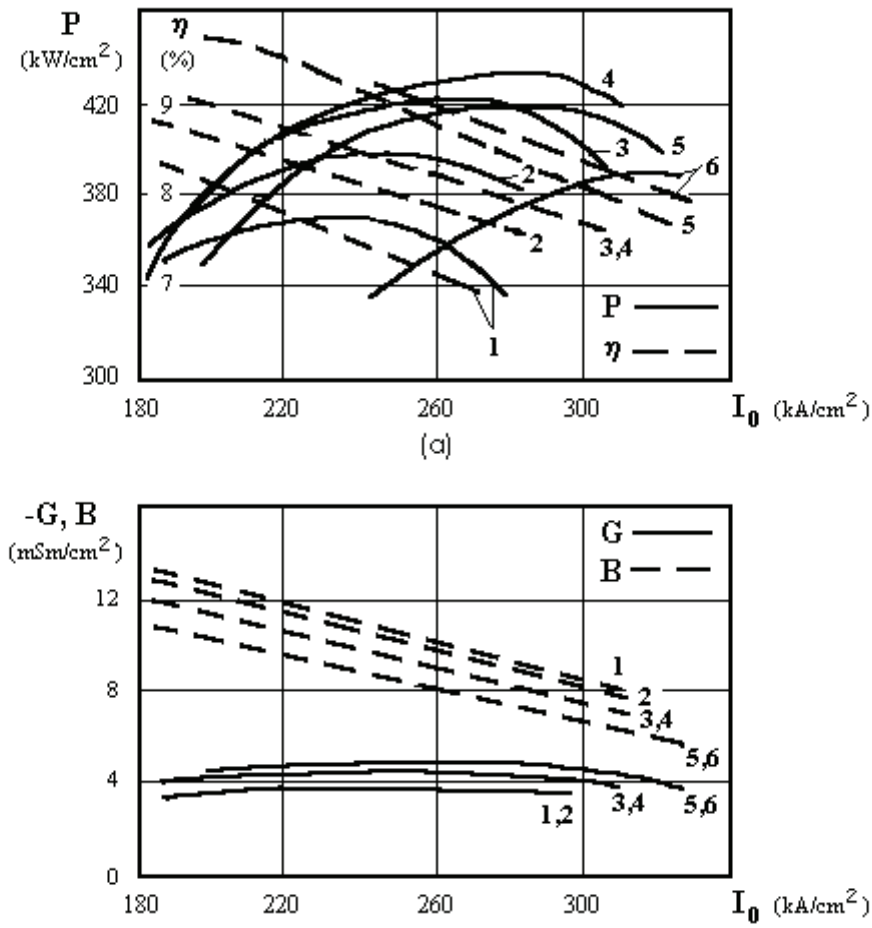

(b)

Fig. 6. (a) Output power P and efficiency coefficient $\eta$, (b) real G and imaginary B parts of the total admittance as functions of feeding current density $I_{0}$ for optimal and near optimal structures with constant doping profile level

\section{2 $140 \mathrm{GHz}$ diode}

In Fig.6 (a), (b) the characteristics of power-level, efficiency, and the real and imaginary parts of the complex admittance of the $140 \mathrm{GHz}$ diode are presented as functions of the feeding current density $I_{0}$ for the optimum structures and for others that are near the optimum. Parameters of the constant doping level and length values for this figure are presented in Table 3. 


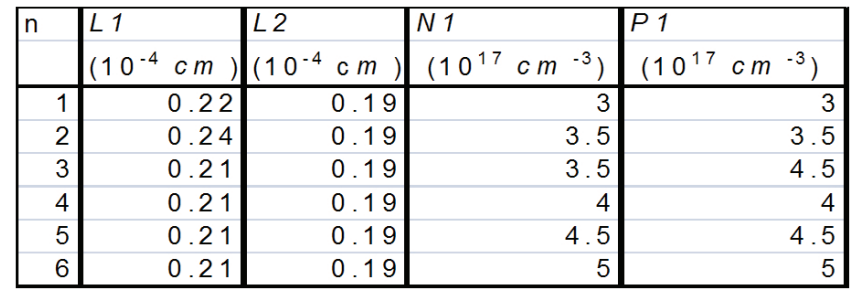

Table 3. Internal structure parameters for diode with constant doping profile for $140 \mathrm{GHz}$

All technological parameters are defined similar to previous section. Structure 4 has a maximum power level of $430 \mathrm{~kW} / \mathrm{cm}^{2}$ and an optimal current density value of $I_{0}=285$ $\mathrm{kA} / \mathrm{cm}^{2}$. In that case, the efficiency is equal to $8.0 \%$ for the maximum power point. Structure 5 has a maximum of the negative real admittance and efficiency $(8.5 \%)$, but has a smaller power level because the doping level is high, and therefore the permanent voltage and first harmonic amplitude voltage are smaller. Structure 6 has a maximum efficiency as the function of the current $I_{0}$, but for the optimum power point, this value is less than for structures 4 and 5 . Besides, for this structure, it is necessary to increase the current value to $320 \mathrm{kA} / \mathrm{cm}^{2}$ to obtain the optimum power point. Structures 5 and 6 have a maximum value of the real part of the total admittance, but have a greater doping level, and therefore a smaller value of the permanent and variable voltage and output power.

Semiconductor structures with a complex doping profile are analyzed for improving the power level and efficiency of the IMPATT diode with a maximum level of permanent current density. Parameters of these structures are presented in Table 4. In Fig. 7 (a), (b) the dependencies of power level, efficiency and admittance are presented as functions of feeding current density $I_{0}$ for the optimum structure and for near optimum ones.

\begin{tabular}{|c|c|c|c|c|c|c|c|c|}
\hline$n$ & $\begin{array}{l}\mathrm{L} 1 \\
\left(10^{-4} \mathrm{~cm}\right.\end{array}$ & \begin{tabular}{|l}
$\mathrm{L} 2$ \\
$\left(10^{-4} \mathrm{~cm}\right)$
\end{tabular} & \begin{tabular}{|l}
$\mathrm{L3}$ \\
$\left(10^{-4} \mathrm{~cm}\right.$
\end{tabular} & \begin{tabular}{|l|}
$\mathrm{L} 4$ \\
$\left(10^{-4} \mathrm{~cm}\right)$
\end{tabular} & \begin{tabular}{|l} 
N1 \\
$\left(10^{17} \mathrm{~cm}^{-3}\right)$
\end{tabular} & \begin{tabular}{|l} 
N2 \\
$\left(10^{17} \mathrm{~cm}^{-3}\right)$
\end{tabular} & \begin{tabular}{|l|} 
P 2 \\
$\left(10^{17} \mathrm{~cm}^{-3}\right)$
\end{tabular} & $\begin{array}{l}\text { P } 1 \\
\left(10^{17} \mathrm{~cm}^{-3}\right)\end{array}$ \\
\hline 1 & 0.09 & 0.08 & 0.11 & 0.06 & 1.6 & 4.7 & 4.1 & 1.6 \\
\hline 2 & 0.09 & 0.08 & 0.11 & 0.06 & 1.5 & 4.7 & 4.7 & 1.5 \\
\hline 3 & 0.09 & 0.08 & 0.11 & 0.06 & 1.6 & 4.7 & 4.1 & 1.4 \\
\hline 4 & 0.09 & 0.08 & 0.11 & 0.06 & 1.6 & 5.2 & 4.6 & 1.6 \\
\hline 5 & 0.08 & 0.09 & 0.12 & 0.05 & 1.6 & 4.7 & 4.1 & 1.6 \\
\hline 6 & 0.07 & 0.08 & 0.11 & 0.04 & 1.6 & 4.7 & 4.1 & 1.6 \\
\hline
\end{tabular}

Table 4. Internal structure parameters for diode with complex doping profile for $140 \mathrm{GHz}$

Structure 1 is the optimal one. In this case, the power level is $457 \mathrm{~kW} / \mathrm{cm}^{2}$, and the optimal current density value is $235 \mathrm{kA} / \mathrm{cm}^{2}$. Others structures are near this optimum one, but have a lower power level and efficiency. The extension of the high doping level parts (structures 4 and 5) results in moving the power curve to a greater current density. These two types of semiconductor structures have a greater value of active admittance than the optimal one, but have a smaller microwave voltage amplitude and power level.

It is very important to compare the optimal characteristics for the two different types of structures as the constant doping profile (curve 4, Fig. 6(a)) and the complex doping profile (curve 1, Fig. 7(a) ). A comparative analysis shows that the maximum output power level is quasiequal for two these optimal structures $\left(436 \mathrm{~kW} / \mathrm{cm}^{2}\right.$ and $\left.452 \mathrm{~kW} / \mathrm{cm}^{2}\right)$, but the efficiency coefficient has more difference $(8.5 \%$ and $10.7 \%)$. The most important fact is a significant decrease of the optimal value of the permanent current density for the complex 
doping structure. For the permanent doping structure, the optimal current density value is $285 \mathrm{kA} / \mathrm{cm}^{2}$, but for the complex doping structure, it is $235 \mathrm{kA} / \mathrm{cm}^{2}$.

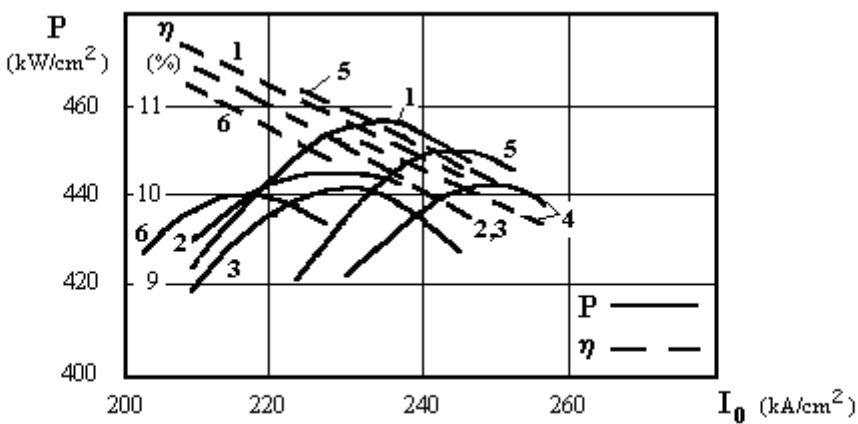

(a)

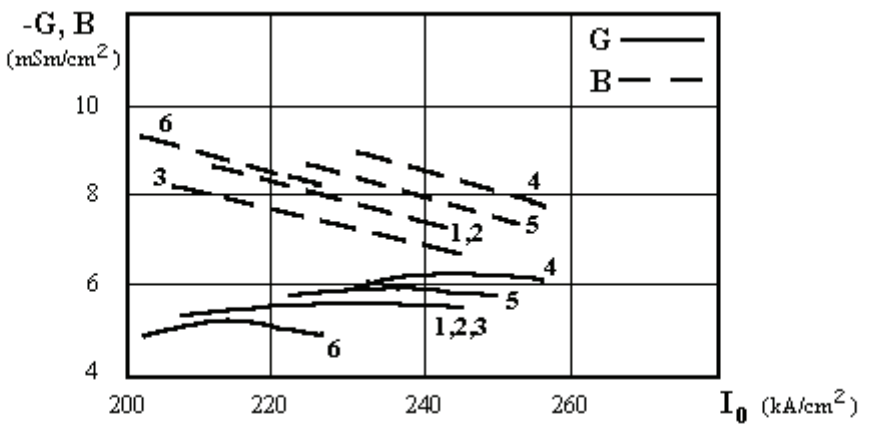

(b)

Fig. 7. (a) Output power P and efficiency coefficient $\eta$ and (b) real G and imaginary B parts of the total admittance as functions of feeding current density $I_{0}$ for optimal and near optimal structures with complex doping profile level

Therefore, the complex doping profile structure has better energy characteristics, and allows the possibility to exploiting the diode under easier conditions.

One of the important problems for the real type of the complex doping profile diode optimization is the sensitivity analysis of energy characteristics for various geometrical sizes and doping levels. The total number of the analyzed structures is very large, because of a large number of combinations of the 8 parameters. Some results of the investigation of an optimal structure by changing the doping profile levels N1, N2, P2, P1 and lengths L1, L2, L3, L4 within 20\% around the optimal structure are presented in Tables 5 and 6, respectively. Presented examples give the possibility to evaluate correctly the technology inaccuracy influence to the energy characteristics deterioration. In these tables, we present the maximum achievable output power density, the permanent current density that corresponds to this optimum, and the real and imaginary parts of the complex admittance. The diode doping profile level increase within $20 \%$ with respect to the optimal structure leads to a small decrease of the output power. On the other hand, the diode doping profile level decrease leads to a great decrease of output power. Some structures (6, 7 of Table 5) 
have a real admittance module greater than the optimal one (number 1), but because the microwave voltage amplitude is decreased, the output power level for these structures is smaller.

\begin{tabular}{|c|c|c|c|c|c|c|c|c|}
\hline $\mathrm{n}$ & N1 & N2 & $P 2$ & $P 1$ & $P_{\text {max }}$ & Iopt & $G$ & $B$ \\
\hline & $\left(10^{17} \mathrm{~cm}^{-3}\right)$ & $\left(10^{17} \mathrm{~cm}^{-3}\right)$ & $\left(10^{17} \mathrm{~cm}^{-3}\right)$ & $\left(10^{17} \mathrm{~cm}^{-3}\right)$ & $\left(\mathrm{kW} / \mathrm{cm}^{2}\right)$ & $\left(\mathrm{kA} / \mathrm{cm}^{2}\right)$ & $\left(m S m / c m^{2}\right)$ & $\left(m \mathrm{Sm} / \mathrm{cm}^{2}\right)$ \\
\hline 1 & 1.6 & 4.7 & 4.1 & 1.6 & 455 & 235 & -5.24 & 7.83 \\
\hline 2 & 1.8 & 4.7 & 4.1 & 1.8 & 451 & 241 & -5.36 & 7.51 \\
\hline 3 & 2 & 4.7 & 4.1 & 2 & 451 & 242 & -5.46 & 7.21 \\
\hline 4 & 1.5 & 4.7 & 4.7 & 1.5 & 448 & 230 & -5.25 & 7.51 \\
\hline 5 & 1.4 & 4.1 & 4.1 & 1.4 & 443 & 227 & -5.21 & 7.35 \\
\hline 6 & 1.6 & 5 & 4.4 & 1.6 & 448 & 241 & -5.71 & 8.07 \\
\hline 7 & 1.6 & 5.2 & 4.6 & 1.6 & 447 & 251 & -6.04 & 8.38 \\
\hline 8 & 1.6 & 4.5 & 3.9 & 1.6 & 443 & 225 & -4.78 & 8.51 \\
\hline 9 & 1.6 & 4.2 & 3.7 & 1.6 & 440 & 227 & -4.43 & 8.67 \\
\hline
\end{tabular}

Table 5. Doping profile level variation within $20 \%$ around the optimal structure and diode output characteristics corresponding to these structures

\begin{tabular}{|c|c|c|c|c|c|c|c|c|}
\hline \multirow[t]{2}{*}{$\mathrm{n}$} & $\angle 1$ & $\angle 2$ & $\angle 3$ & $L 4$ & $P_{\text {max }}$ & I opt & G & \multirow{2}{*}{$\begin{array}{l}B \\
\left(m S m / c m^{2}\right)\end{array}$} \\
\hline & $\left(10^{-4} \mathrm{~cm}\right)$ & $\left(10^{-4} \mathrm{~cm}\right)$ & $\left(10^{-4} \mathrm{~cm}\right)$ & $\left(10^{-4} \mathrm{~cm}\right)$ & $\left(k W / c^{2}\right)$ & $\left(\mathrm{k} A / \mathrm{cm}^{2}\right)$ & $\left(m S m / c m^{2}\right)$ & \\
\hline \multirow{2}{*}{$\begin{array}{l}1 \\
2\end{array}$} & 0.09 & 0.08 & 0.11 & \begin{tabular}{|l|}
0.06 \\
\end{tabular} & 455 & 235 & -5.24 & 7.83 \\
\hline & 0.08 & 0.09 & 0.12 & 0.05 & 451 & 245 & -5.51 & 7.91 \\
\hline 3 & 0.07 & 0.1 & 0.13 & 0.04 & 447 & 253 & -5.61 & 8.11 \\
\hline 4 & 0.1 & 0.07 & 0.1 & 0.07 & 450 & 230 & -4.97 & 8.11 \\
\hline 5 & 0.11 & 0.06 & 0.09 & 0.08 & 445 & 225 & -4.85 & 8.44 \\
\hline & - I., & $1 \ldots .388$ & & 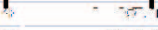 & 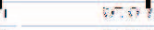 & \multirow{2}{*}{0.09} & 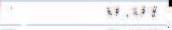 & 2,00 \\
\hline \multicolumn{2}{|c|}{$222 \$ 3$} & A 835 & 8.14 & 0.11 & 0.06 & & 0.08 & $1 / 15$ \\
\hline & 232 & $\therefore 8.17$ & 7.11 & (1). 1 & 0.08 & 0.11 & $0.0 \%$ & 480 \\
\hline \multicolumn{2}{|r|}{233} & -4.91 & 6.831 & 0.11 & (0.08: & 0.1 & 0.088 & 448 \\
\hline
\end{tabular}

Table 6. Length variation within $20 \%$ around the optimal structure and diode output characteristics corresponding to these structures

An analysis of the results that are presented in Table 6 shows that the variation of the total length $L=x 9-x 1$ around the optimal value leads to a great deterioration of the energy characteristics (structures 8 and 9). On the other hand, the redistribution of separate part's dimensions between the high and low doping profile parts within $20 \%$ has not led to a great decrease of the output power level.

\section{DAR diode analysis}

\subsection{Numerical scheme convergence}

The analysis of numerical scheme (5)-(6) for different DDR IMPATT diode showed a good convergence of the numerical model. The convergence was obtained during $6-8$ periods.

The analysis of numerical model for the DAR type of the doping profile (Fig. 2) gave unexpected but understandable results. The numerical scheme convergence for this type of the doping profile is very slow. The quantitative results of the numerical scheme convergence for the principal diode characteristic, DAR diode conductance as the period number function are shown in Fig. 8. The necessary number of the consequent periods depends on the operating frequency and can change from $30-50$ for the frequency region $15-60 \mathrm{GHz}$ up to $150-250$ periods for $200-300 \mathrm{GHz}$. This very slow convergence is stipulated by the asynchronies movement of the electron and hole avalanches along the 
same transit time region $v$. It occurs owing to the different drift velocities of the carriers. This type of the numerical convergence provokes a large number of necessary periods and a large computer time. We need to declare that the bad convergence result is the feature of the diode mathematical numerical scheme and is not the physical diode property. The physical stability is discussed in detail below.

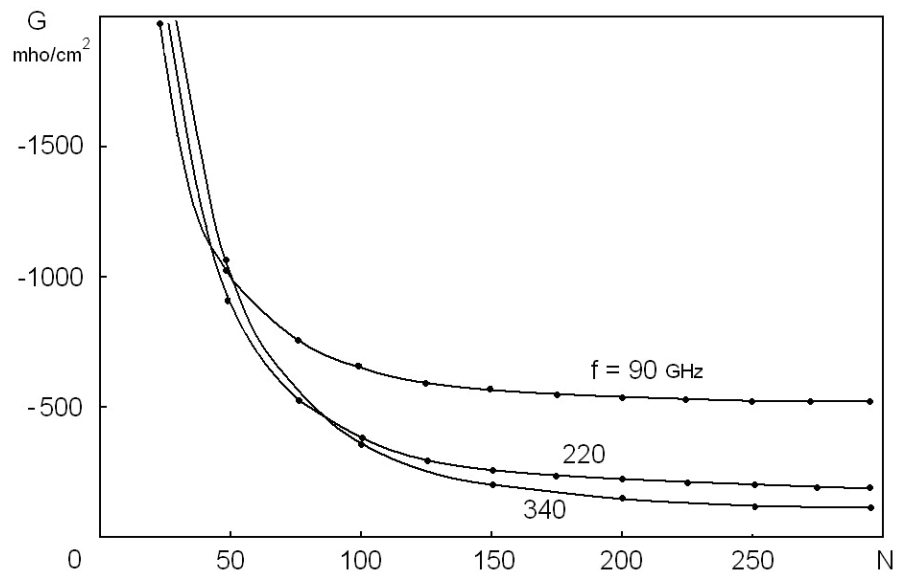

Fig. 8. Calculated conductance as function of period number $N$

\subsection{Results}

The analysis of DAR IMPATT diode provided some yeas ago shown interesting and at the same time very surprising results concerning main features of the DAR diodes. One of the important conclusions of these works concerns of the drift zone width $v$ influence to the diode frequency characteristics. It is noted that the diode active properties are produced practically for any drift zone width and this width has an influence on the number of the frequency bands. The larger drift zone provokes more number of frequency bands. Some of these results were obtained by means of the small signal model (Som et al., 1974; Datta \& Pal, 1982; Datta et al., 1982). Other results (Pati et al., 1991; Panda et al., 1995) were obtained on the basis of simplified nonlinear model. We suppose that it is necessary to analyze this diode by means of precise model described in section 2.1 (Zemliak \& De La Cruz, 2006).

The DAR diode doping profile was defined the same as in paper (Panda et al., 1995) for primary analysis to provide the adequate comparison between results which were obtained by two different approaches. Then the accurate analysis for DAR IMPATT diode has been made for different values of $p, n$ and $v$ region width and the different donor and acceptor concentration level. The analysis showed that the active properties of the diode practically are not displayed for more or less significant width of the region $v$. The same doping profile as in (Panda et al., 1995) gives the negative conductance for very narrow frequency band only as shown in Fig. 9 in conductance versus susceptance plot.

The solid line of this figure gives dependency for drift layer width $W_{v}=0.6 \mu \mathrm{m}$ and the dash line for $W_{v}=1.5 \mu \mathrm{m}$. First dependency displays the diode active properties for one narrow frequency band from $50 \mathrm{GHz}$ up to $85 \mathrm{GHz}$. Second admittance dependency for $W_{v}=1.5 \mu \mathrm{m}$ gives very narrow one frequency band from $40 \mathrm{GHz}$ up to $62 \mathrm{GHz}$ with a vary small value of negative conductance $G$. In general the admittance behavior has a damp oscillation 
character but only first peak lies in negative semi plane. The negative conductance disappears completely for $W_{v}>1.5 \mu \mathrm{m}$. All these results have been obtained in assumption of a sufficiently small value of a series resistance $R_{s}=0.5_{10}-6 \mathrm{Ohm} \cdot \mathrm{cm}^{2}$. This value was used for all further analysis too.

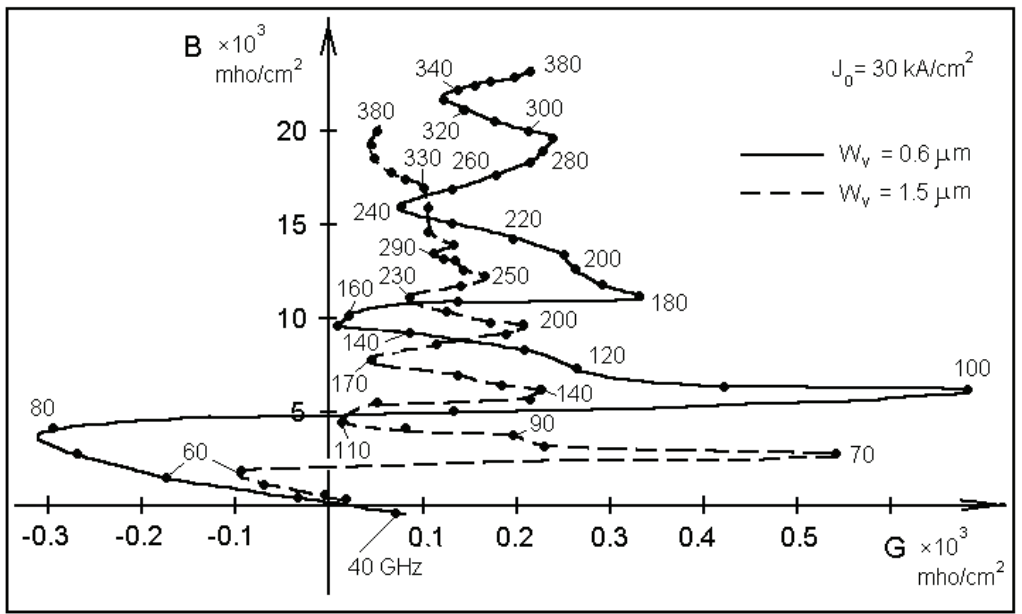

Fig. 9. Complex small signal DAR diode admittance (conductance $-G$ versus susceptance $B$ ) for different frequencies and two values of drift layer widths $W_{v}$

The main reason of obtained characteristics behavior is the same as for the slow mechanism convergence of the numerical model. The electron and hole avalanches have different transit velocities but they move along the same drift region $v$. It provokes different time delay for the carriers during the transit region movement. The larger width of the region $v$ makes delay time more different and the active properties are reduced. That is why we need to reduce the width $W_{v}$ to obtain necessary negative admittance. This conclusion is contrary to results of the papers (Pati et al., 1991; Panda et al., 1995). The main results obtained by these authors showed the DAR diode active features presence in some frequency bands for different values of $v$ region widths from $0.5 \mu \mathrm{m}$ to $2.0 \mu \mathrm{m}$. Our results display the active features of the DAR diode the same profile for some frequency bands in case when the $v$ region width less than $0.5 \mu \mathrm{m}$ only. The obtained difference could be explained probably by means of approximate numerical model used in paper (Panda et al., 1995). One modified Runge-Kutta method was used to mathematical model solve as shown in this paper. However it is known that any explicit numerical method like Runge-Kutta does not have the necessary stability to solve the sufficiently difficult problem (1) with a very sharp dependency of ionization coefficients.

One positive idea to increase negative admittance of the diode consists in non-symmetric doping profile utilization too. This profile gives some compensation to the asynchronies mechanism. Taking into account these considerations non-symmetric doping profile diode was analyzed in a wide frequency band. One of the perspective diode structures that was analyzed detail is defined by means of following parameters: the doping level of the $n$-zone is equal to $0.5_{10} 17 \mathrm{~cm}^{-3}$, the doping level of the $p$-zone is equal to $0.2_{10} 17 \mathrm{~cm}^{-3}$, the widths of the two corresponding areas are equal to $0.1 \mu \mathrm{m}$ and $0.2 \mu \mathrm{m}$, accordingly, the width of the 
drift $v$-region is equal to $0.32 \mu \mathrm{m}$, the width of each $p$ - $n$ junction was given as $0.02 \mu \mathrm{m}$ from the technological aspects. This structure provides concentration of electrical field within the two $p-n$ junctions and asynchronies mechanism is not displayed drastically yet.

In Fig. 10 the small signal complex admittance i.e. the conductance versus susceptance is presented for the wide frequencies band for DAR diode and for the current density $J_{0}=30$ $\mathrm{kA} / \mathrm{cm}^{2}$. The DC voltage $U_{0}$ is equal to $26.59 \mathrm{~V}$ with a small variation from one frequency to other to obtain this value of current density. The first harmonic voltage amplitude is equal to $0.1 \mathrm{~V}$.

There are some differences of the DAR diode frequency characteristics from the classical DDR IMPATT diodes. First of all the DAR diode type has three active bands in the millimeter range (Fig.10) and the DDR diode has only one band. The first active band of the DAR diode is very wide and covers frequency region from 12 to $138 \mathrm{GHz}$. The second and the third bands give the perspective to use this structure for the high frequency generation in the millimeter range too. We can decide that two superior bands appear from the positive conductance G semi plane (look Fig. 9) as a result of the special conditions making for these bands. This effect gives possibility to use superior frequency bands, at least the second band, for the microwave power generation of the sufficient level. The dependences of conductance $-G$ as the function of the first harmonic amplitude $U_{1}$ are shown in Fig. 11 for three frequency bands and for the same value of the current density $J_{0}=30 \mathrm{kA} / \mathrm{cm}^{2}$.

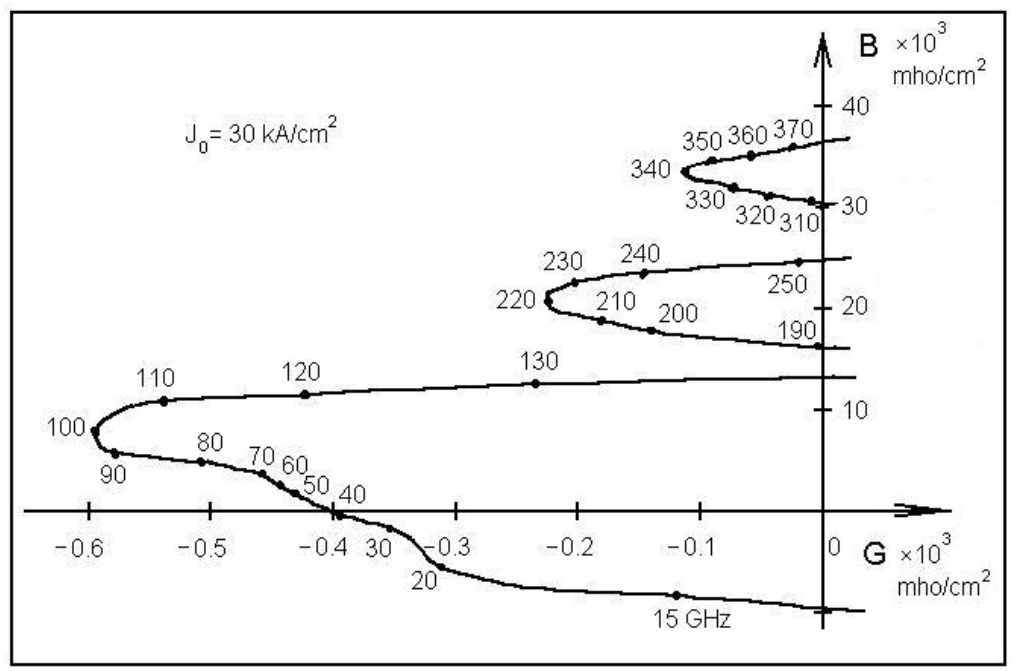

Fig. 10. Complex small signal DAR diode admittance (conductance $-G$ versus susceptance $B$ ) for different frequencies and $W_{v}=0.32 \mu \mathrm{m}$

It is clear that the first frequency band characteristic $(f=90 \mathrm{GHz})$ has a better behavior. The maximum value of the conductance $-G$ is large and achieves nearly the $600 \mathrm{mho} / \mathrm{cm}^{2}$ under the small signal. The amplitude dependency for the first band is very soft and this provides a significant value of the generated power. Nevertheless the second and the third bands (for $220 \mathrm{GHz}$ and for $340 \mathrm{GHz}$ ) have the perspective too. The output power dependences for two frequency bands are presented in Fig. 12 as functions of the first harmonic amplitude. 


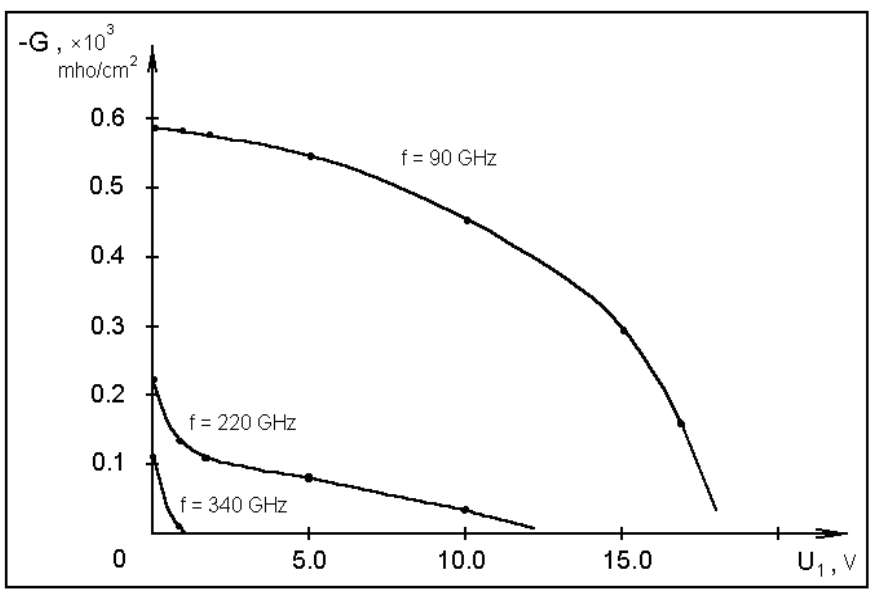

Fig. 11. Conductance $G$ dependence as functions of first harmonic amplitude $U_{1}$ for different frequency bands

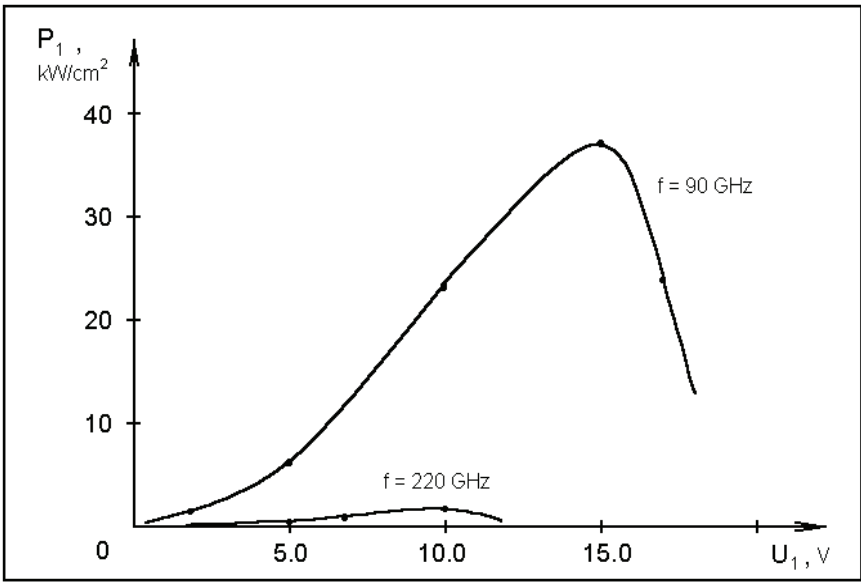

Fig. 12. Output power $P$ dependence as functions of first harmonic amplitude $U_{1}$ for different frequency bands

The maximum power density is equal to $37 \mathrm{~kW} / \mathrm{cm}^{2}$ for the first frequency band $(90 \mathrm{GHz})$, and $1.4 \mathrm{~kW} / \mathrm{cm}^{2}$ for the second one $(220 \mathrm{GHz})$. One principal limit of output power for second and third bands is based on the sharp amplitude dependency as shown in Fig. 11. However possible optimization of the diode internal structure for selected frequency band can improve these characteristics and permits raise the power and the efficiency.

The DAR diode internal structure optimization has been provided below for the second frequency band near $220 \mathrm{GHz}$ and for the third frequency band near $330 \mathrm{GHz}$ separately. The optimization algorithm is combined by one kind of direct method and a gradient method and was described in section 3.

The cost function of the second frequency band optimization process was selected as output power for frequency $220 \mathrm{GHz}$. It means that the energy characteristics for the first and the 
third frequency bands have been obtained as functions of a secondary interest without a special improvement. The set of the variables for the optimization procedure was composed from five technological parameters of the diode structure: two doping levels for $p$ and $n$ regions and three widths of $p, n$ and $v$ regions. The optimal values of these parameters are following: doping level of the $n$-zone is equal to $0.421017 \mathrm{~cm}^{-3}$, the doping level of the $p$-zone is equal to $0.28_{10} 17 \mathrm{~cm}^{-3}$, the widths of the two corresponding areas are equal to $0.1 \mu \mathrm{m}$ and $0.2 \mu \mathrm{m}$, accordingly, and the width of the drift $v$-region is equal to $0.34 \mu \mathrm{m}$, The internal structure optimization of second frequency band has been made for the feeding current density $30 \mathrm{kA} / \mathrm{cm}^{2}$. However it is interesting to calculate the diode power characteristics for other current density too. The complete analysis was done for three current density values: $30 \mathrm{kA} / \mathrm{cm}^{2}, 50 \mathrm{kA} / \mathrm{cm}^{2}$ and $70 \mathrm{kA} / \mathrm{cm}^{2}$. Although the structure optimization was provided for the large signal, the small signal diode admittance dependency is an interest too. These small signal characteristics are shown in Fig. 13 for all possible frequency bands and three values of feeding current density.

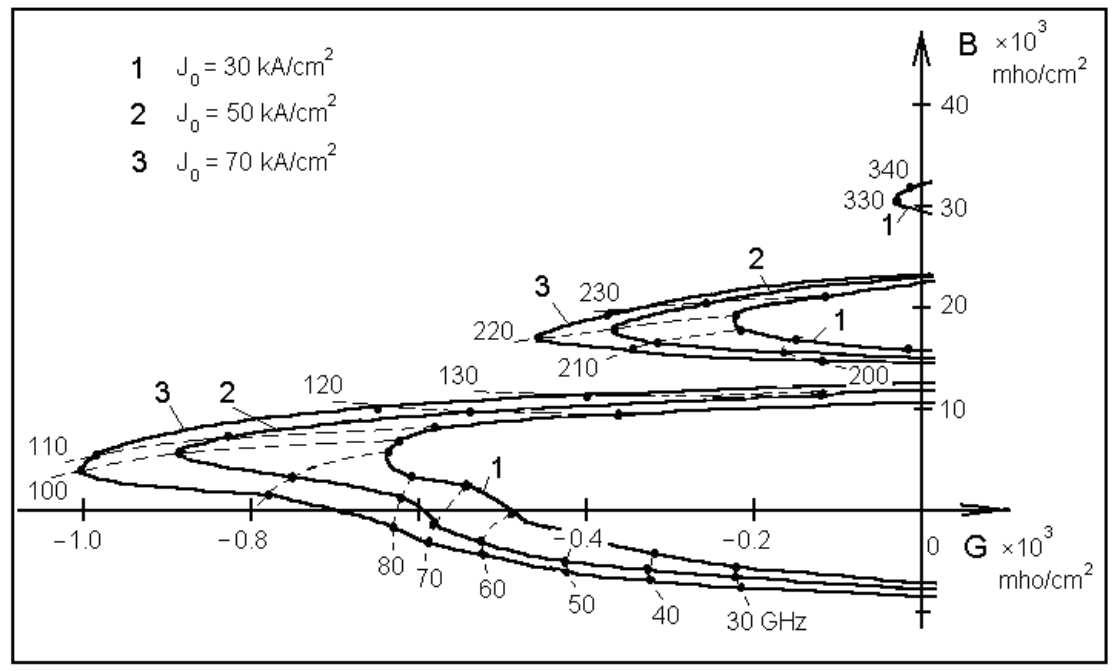

Fig. 13. Complex small signal DAR diode admittance optimized for second frequency band for different value of feeding current density

The active diode properties for two first bands are improved when the current density increases. Because the technological parameters have been optimized for $220 \mathrm{GHz}$ more positive effect was obtained for this frequency. At the same time the third frequency band practically disappears. The maximum value of diode conductance for more favorable frequency $330 \mathrm{GHz}$ is equal to $-30 \mathrm{mho} / \mathrm{cm}^{2}$ for the structure optimized for the second band. On the other hand the diode conductance is equal to $-120 \mathrm{mho} / \mathrm{cm}^{2}$ for $340 \mathrm{GHz}$ for before analyzed structure in Fig. 10. Further current density increasing leads to complete disappearance of the active properties for this frequency.

The characteristics obtained for $220 \mathrm{GHz}$ under the large signal serve as the main result of the optimization process. The amplitude characteristics for this frequency and for three values of feeding current density are shown in Fig. 14. 


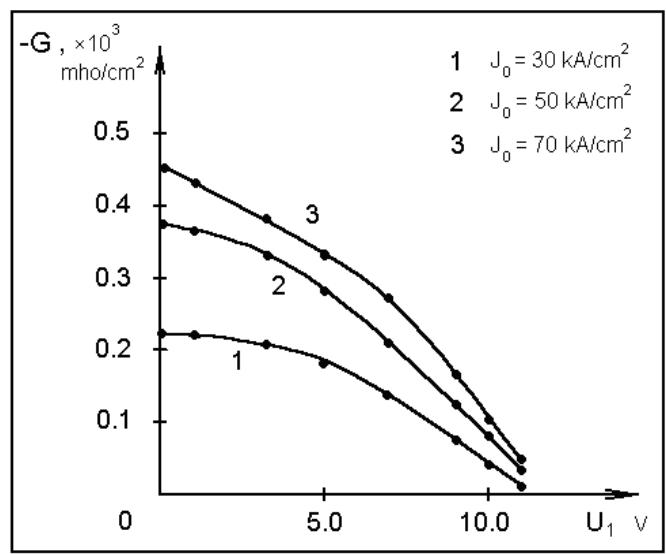

Fig. 14. Conductance $G$ dependence as functions of first harmonic amplitude $U_{1}$ for $f=220$ $\mathrm{GHz}$ and for three values of feeding current density

Because the diode structure optimization was provided for current density $30 \mathrm{kA} / \mathrm{cm}^{2}$ the amplitude characteristic that corresponds to this current has better behavior in comparison to others. This characteristic is softer. Characteristics for current densities $50 \mathrm{kA} / \mathrm{cm}^{2}$ and 70 $\mathrm{kA} / \mathrm{cm}^{2}$ are sharper but correspond to larger conductance $-\mathrm{G}$. As a result this property gives a larger output generated power. The characteristics that correspond to two last current density values can be made better if the optimization process realize for each of this current value. The output power dependencies as a function of first harmonic amplitude $U_{1}$ for $\mathrm{f}=$ $220 \mathrm{GHz}$ and for three values of feeding current density are shown in Fig. 15.

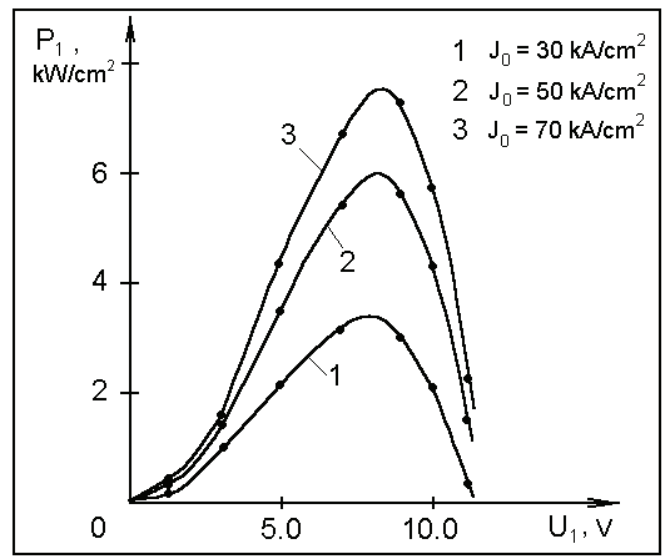

Fig. 15. Output generated power $P$ dependence as functions of first harmonic amplitude $U_{1}$ for $\mathrm{f}=220 \mathrm{GHz}$ and for three values of feeding current density

We can state that a sufficient improvement of power characteristics is observed for this diode structure in comparison with before analyzed structure. The maximum values of generated power are equal to $3.3 \mathrm{~kW} / \mathrm{cm}^{2}$ for $J_{0}=30 \mathrm{kA} / \mathrm{cm}^{2}, 6.0 \mathrm{~kW} / \mathrm{cm}^{2}$ for $J_{0}=50$ 
$\mathrm{kA} / \mathrm{cm}^{2}$ and $7.5 \mathrm{~kW} / \mathrm{cm}^{2}$ for $J_{0}=70 \mathrm{kA} / \mathrm{cm}^{2}$ accordingly. These results were obtained taking into account the series resistance $R_{s}=0.5_{10}-6 \mathrm{Ohm} \cdot \mathrm{cm}^{2}$. The increase of this resistance up to $1.0_{10}-6 \mathrm{Ohm} \cdot \mathrm{cm}^{2}$ gives reduction of the conductance and the generated power from 5 times for $J_{0}=30 \mathrm{kA} / \mathrm{cm}^{2}$ to 2 times for $J_{0}=70 \mathrm{kA} / \mathrm{cm}^{2}$. However it is possible provide the diode structure optimization for large value of the current density. In this case we can obtain a significant level of output generated power again.

The power level optimization for the third frequency band has been provided below. The cost function of the third frequency band optimization process was selected as output power for the frequency $330 \mathrm{GHz}$ and for two values of the feeding current density as $50 \mathrm{kA} / \mathrm{cm}^{2}$ and $70 \mathrm{kA} / \mathrm{cm}^{2}$. The results of the analysis and optimization of small signal admittance for third frequency band are shown in Fig. 16 for two current density values: $50 \mathrm{kA} / \mathrm{cm}^{2}$ and 70 $\mathrm{kA} / \mathrm{cm}^{2}$.

The set of the variables for the optimization procedure was composed from five technological parameters of the diode structure: two doping levels for $p$ and $n$ regions and three widths of $p, n$ and $v$ regions.

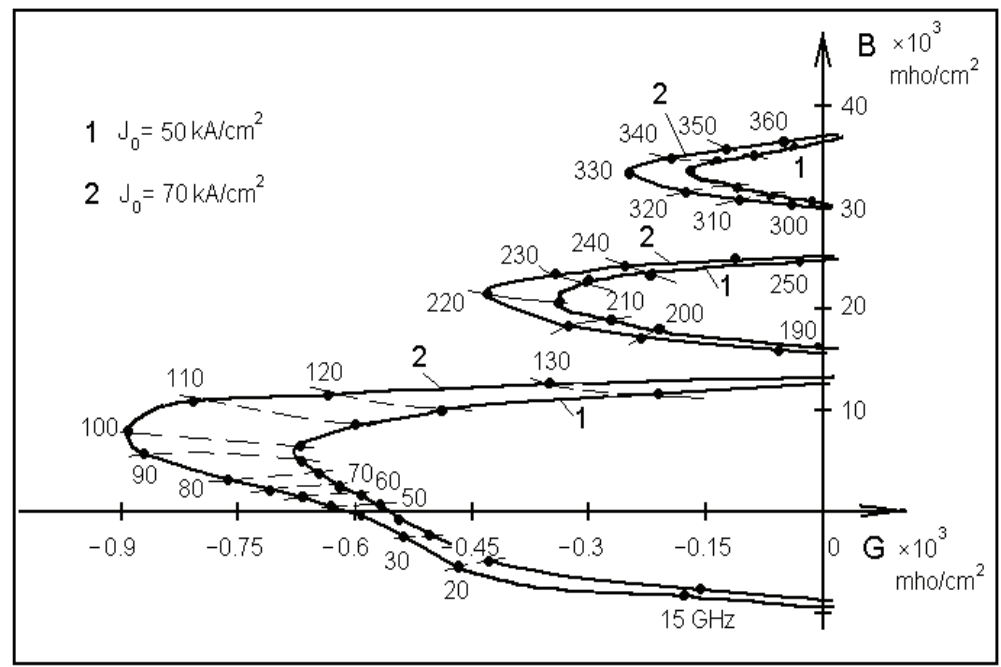

Fig. 16. Complex small signal DAR diode admittance optimized for third frequency band for two values of feeding current

The optimal values of these parameters are next: doping levels of $n$ and $p$ zone are equal to $0.481017 \mathrm{~cm}^{-3}$ and $0.361017 \mathrm{~cm}^{-3}$ accordingly, the widths of the two corresponding areas are equal to $0.09 \mu \mathrm{m}$ and $0.18 \mu \mathrm{m}$, and the width of the drift $v$-region is equal to $0.32 \mu \mathrm{m}$.

The active diode properties for all frequency bands are improved when the current density increases. More positive effect was obtained for the frequency $330 \mathrm{GHz}$ because the optimization for this frequency.

The characteristics obtained for $330 \mathrm{GHz}$ under a large signal serve as the main result. The amplitude characteristics of the conductance for this frequency are shown in Fig. 17 for two values of the current density. 


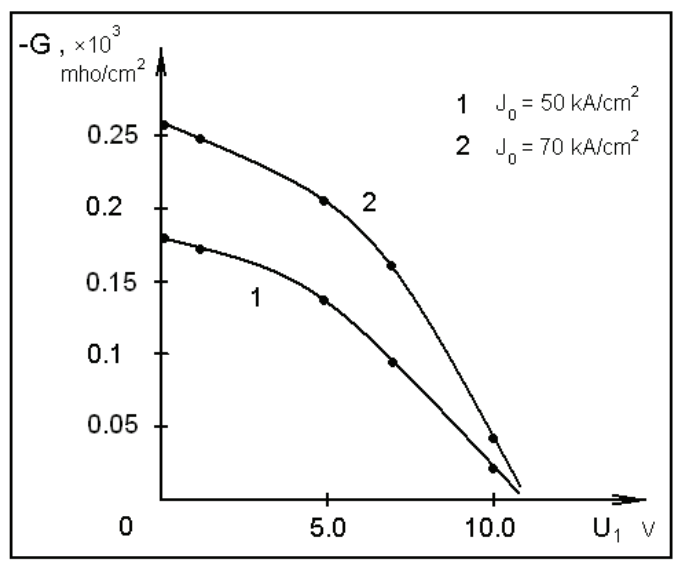

Fig. 17. Conductance $G$ dependence as functions of first harmonic amplitude $U_{1}$ for $f=330$ $\mathrm{GHz}$ and for two values of feeding current density

The conductance characteristic is softer for current density $50 \mathrm{kA} / \mathrm{cm}^{2}$ because the diode structure optimization was provided for this current. The characteristics for $70 \mathrm{kA} / \mathrm{cm}^{2}$ are sharper but correspond to the larger conductance $-G$.

The output power dependencies as a function of first harmonic amplitude $U_{1}$ for $f=330$ $\mathrm{GHz}$ and for two values of feeding current are shown in Fig. 18.

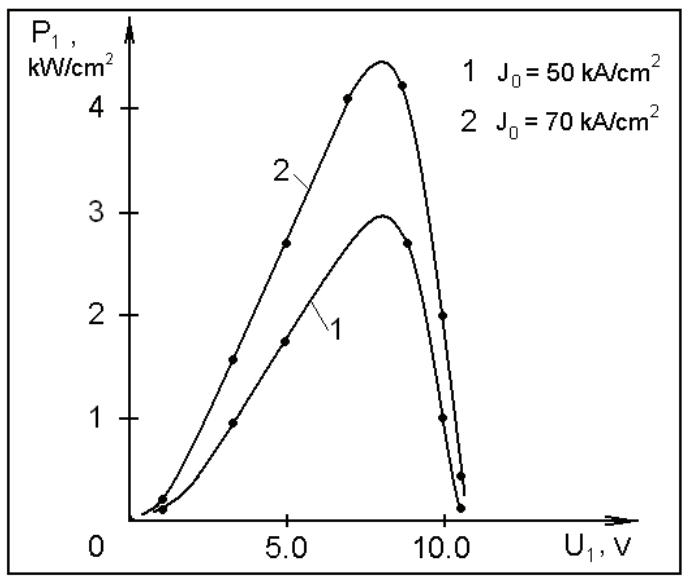

Fig. 18. Output generated power $P$ dependence as functions of first harmonic amplitude $U_{1}$ for $\mathrm{f}=330 \mathrm{GHz}$ and for two values of feeding current density

These amplitude characteristics show the possibility to obtain a sufficient level of output power near the $4 \mathrm{~kW} / \mathrm{cm}^{2}$. 


\section{Conclusion}

The numerical scheme that has been developed for the analysis of the different types of IMPATT diodes is suitable for the DDR and DAR complex doping profile investigation but in case of the DAR diode the numerical scheme convergence is slower.

Some new features of the DAR diode were obtained by the analysis on the basis of nonlinear model. The principal obtained results show that the diode does not have the active properties in some frequency bands for the sufficiently large drift region. To obtain the negative conductance for some frequency bands we need to reduce the drift layer widths significantly. Nevertheless the diode has a wide first frequency band generation and two superior frequency bands with sufficient output power level. The DAR diode analysis gives us the possibility to increase the output power level for the second and third frequency bands. The diode structure optimization gives the possibility to improve the admittance characteristics for high frequency bands.

\section{References}

Bakhvalov, N.S.; Zhidkov, N.P. \& Kobelkov, G.M. (2008). Numerical Methods, Binom, ISBN 978-5-94774-815-4, Moscow.

Canali, C.; Jacoboni, C., Ottaviani, G. \& Alberigi Quaranta, A. (1975). High Field Diffusion of Electrons in Silicon. Appl. Phys. Lett., Vol. 27, p. 278.

Chang K. (Ed), (1990). Handbook of Microwave and Optical Components, Vol. 1, John Wile \& Sons, N.Y..

Curow, M. (1994). Proposed GaAs IMPATT Devices Structure for D-band Applications. Electron. Lett., Vol.30, pp. 1629-1631.

Dalle, C. \& Rolland, (1989). Drift-Diffusion Versus Energy Model for Millimetric-Wave IMPATT Diodes Modelling. Int. J. Numer. Modelling, Vol. 2, pp. 61-73.

Datta D.N. \& Pal B.B. (1982). Generalized small signal analysis of a DAR IMPATT diode. Solid-State Electron., Vol. 25, No. 6, pp. 435-439.

Datta D.N., Pati S.P., Banerjee J.P., Pal B.B. \& Roy S.K. (1982). Computer analysis of DC field and current-density profiles of DAR IMPATT diode. IEEE Trans Electron Devices, Vol. ED-29, pp. 1813-1817.

El-Gabaly, M.A., Mains, R.K. \& Haddad, G.I. (1984). Effects of Doping Profile on GaAs Double-Drift IMPATT Diodes at 33 and $44 \mathrm{GHz}$ Using the Energy-Momentum Transport Model. IEEE Trans., Vol. MTT-32, No.10, pp.1353-1361.

Fong, T.T. \& Kuno, H.J. (1979). Millimeter-Wave Pulsed IMPATT Sourse. IEEE Trans., Vol. MTT-27, No.5, pp. 492-499.

Grant, W.N. (1973). Electron and Hole Ionization Rates in Epitaxial Silicon at High Electric Fields. Solid-State Electronics, Vol.16, No. 10, pp. 1189-1203.

Howes, M.J. \& Morgan, D.V. (Eds.) (1978). Microwave Devices.Devices Circuit Interactions, John Wiley \& Sons, N.Y.

Jacoboni, C., Canali, C., Ottaviani, G. \& Alberigi Quaranta, A. (1977). A Review of Some Charge Transport Properties of Silicon. Solid-State Electron., Vol. 20, pp. 77-89. 
Joshi, R.P., Pathak, S. \& Mcadoo, J.A. (1995). Hot-Electron and Thermal Effects on the Dynamic Characteristics of Single-Transit SiC Impact-Ionization Avalanche TransitTime Diodes. J. Appl. Phys., Vol. 78, pp. 3492-3497.

Kafka, H.J. \& Hess, K. (1981). A Carrier Temperature Model Simulation of a Double-Drift IMPATT Diode. IEEE Trans., ED-28, No.7, pp. 831-834.

Krylov, V.I., Bobkov, V.V. \& Monastyrski, P.I. (1977). Numerical Methods, Nauka, Moscow.

Nava, F., Canali, C., Reggiani, L., Gasquet, D., Vaissiere, J.C. \& Nougier, J.P. (1979). On Diffusivity of Holes in Silicon. J. Appl. Phys., Vol. 50, p. 922.

Panda A.K., Dash G.N. \& Pati S.P. (1995). Computer-aided studies on the wide-band microwave characteristics of a silicon double avalanche region diode. Semicond Sci Technol., Vol. 10, pp.854-864.

Pati, S.P., Banerjee, J.P. \& Roy, S.K. (1991). High frequency numerical analysis of double avalanche region IMPATT diode, Semicond Sci Technol, No. 6, pp. 777-783.

Read, W.T. (1958). A Proposed High-Frequency Negative-Resistance Diode. Bell System Tech. J., Vol. 37, pp. 401-406.

Scharfetter, D.L. \& Gummel, H.K. (1969). Large-Signal Analysis of a Silicon Read Diode Oscillator. IEEE Trans., Vol. ED-16, No.1, pp. 64-77.

Som B., Pal B.B. \& Roy S.K. (1974). A small signal analysis of an IMPATT device having two avalanche layers interspaced by a drift layer. Solid-State Electron., Vol. 17, pp. 10291038.

Stoiljkovic, V., Howes, M.J. \& Postoyalko, V. (1992). Nonisothermal Drift-Diffusion Model of Avalanche Diodes. J. Appl. Phys., Vol.72, pp. 5493-5495.

Tager A.S., \& Vald-Perlov, V.M. (1968). Avalanche Diodes and Application on Microwave Endineering, Sov. Radio, Moscow.

Tornblad, O., Lindefelt, U. \& Breitholtz, B. (1996). Heat Generation in Si Bipolar Power Devices: the Relative Importance of Various Contributions. Solid State Electronics, Vol.39, No.10, pp. 1463-1471.

Vasilevskii, K.V. (1992). Calculation of the Dynamic Characteristics of a Silicon Carbide IMPATT Diode, Sov. Phys. Semicond., Vol.26, pp. 994-999.

Zemliak, A.M. (1981). Difference Circuit Stability Analysis for IMPATT-Diode Design. Izvestiya VUZ Radioelectronica, Vol.24, No.8, pp. 88-89.

Zemliak, A.M. \& Zinchenko, S.A. (1989). Non-Linear Analysis of IMPATT Diodes. Vestnik K.P.I., Radiotechnika, Vol.26, pp. 10-14.

Zemliak, A.M. \& Roman, A.E. (1991). IMPATT Diode for the Pulsed-Mode. Izvestiya VUZ Radioelectronica, Vol. 34, No. 10, pp.18-23.

Zemliak, A., Khotiaintsev, S. \& Celaya, C. (1997). Complex Nonlinear Model for the Pulsed-Mode IMPATT Diode. Instrumentation and Development, Vol. 3, No. 8, pp. 4552.

Zemliak A., Celaya C. \& Garcia R. (1998). Active layer parameter optimization for highpower Si $2 \mathrm{~mm}$ pulsed IMPATT diode. Microwave and Opt Technol Lett., Vol. 19, No. 1, pp. 4-9.

Zemliak A. \& De La Cruz R. (2002). An analysis of the active layer optimization of high power pulsed IMPATT diodes. Comput $\mathcal{E}$ Systems., No. 6, pp. 99-107. 
Zemliak, A.M. \& De La Cruz, R. (2006). Numerical analysis of a double avalanche region IMPATT diode on the basis of nonlinear model. Microelectronics Reliability, Vol. 46, No. 2-4, pp. 293-300. 


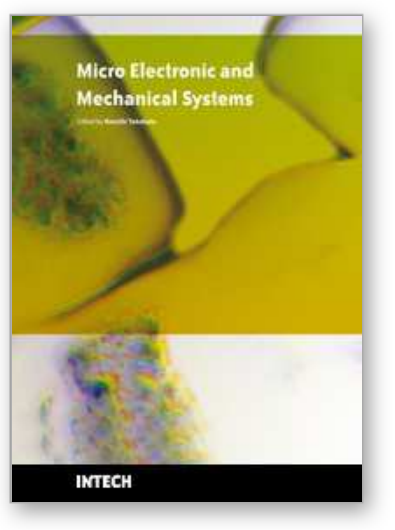

\author{
Micro Electronic and Mechanical Systems \\ Edited by Kenichi Takahata
}

ISBN 978-953-307-027-8

Hard cover, 386 pages

Publisher InTech

Published online 01, December, 2009

Published in print edition December, 2009

This book discusses key aspects of MEMS technology areas, organized in twenty-seven chapters that present the latest research developments in micro electronic and mechanical systems. The book addresses a wide range of fundamental and practical issues related to MEMS, advanced metal-oxide-semiconductor (MOS) and complementary MOS (CMOS) devices, SoC technology, integrated circuit testing and verification, and other important topics in the field. Several chapters cover state-of-the-art microfabrication techniques and materials as enabling technologies for the microsystems. Reliability issues concerning both electronic and mechanical aspects of these devices and systems are also addressed in various chapters.

\title{
How to reference
}

In order to correctly reference this scholarly work, feel free to copy and paste the following:

Alexander Zemliak (2009). Comparative Analysis of High Frequency Characteristics of DDR and DAR IMPATT Diodes, Micro Electronic and Mechanical Systems, Kenichi Takahata (Ed.), ISBN: 978-953-307-027-8, InTech, Available from: http://www.intechopen.com/books/micro-electronic-and-mechanical-systems/comparativeanalysis-of-high-frequency-characteristics-of-ddr-and-dar-impatt-diodes

\section{INTECH}

open science | open minds

\section{InTech Europe}

University Campus STeP Ri

Slavka Krautzeka 83/A

51000 Rijeka, Croatia

Phone: +385 (51) 770447

Fax: +385 (51) 686166

www.intechopen.com

\section{InTech China}

Unit 405, Office Block, Hotel Equatorial Shanghai

No.65, Yan An Road (West), Shanghai, 200040, China

中国上海市延安西路65号上海国际贵都大饭店办公楼405单元

Phone: +86-21-62489820

Fax: +86-21-62489821 
(C) 2009 The Author(s). Licensee IntechOpen. This chapter is distributed under the terms of the Creative Commons Attribution-NonCommercialShareAlike-3.0 License, which permits use, distribution and reproduction for non-commercial purposes, provided the original is properly cited and derivative works building on this content are distributed under the same license. 